\section{O desafio da integração social no MERCOSUL: uma discussão sobre a cidadania e o direito à saúde}

\author{
The challenge of social integration in the \\ MERCOSUR: a discussion on citizenship \\ and the right to health
}

Keli Regina Dal Prá ${ }^{1}$

Jussara Maria Rosa Mendes 1

Regina Célia Tamaso Mioto 2

\section{Introdução}

This article discusses the guarantee of the right to health care and the exercise of citizenship in border areas between Brazil and the other MERCOSUR member countries, considering cross-border movement of persons and the demand on the Brazilian National Health System (SUS) by the population living along the borders. The goal is to debate the guarantee of the right to health, citizenship, free circulation of persons, and territoriality, since these issues correlate with the circulation of border-area populations in Brazilian municipalities. The article identifies the predominance of the economic dimension in the MERCOSUR. The analysis relates to national citizenship and territory when extending the right to health care to the cross-border population. The article also considers alternatives to the extension of such rights and the definition of public health care policies along the MERCOSUR border in order to meet the demand for services provided by the SUS.

Right to Health; Border Areas; Health Policy
As fronteiras do MERCOSUL têm sido marcadas pelo trânsito expressivo de pessoas vindas do Paraguai, Argentina e Uruguai em busca de serviços de saúde pública no Brasil 1. O trânsito interfronteiriço tem evidenciado questões a respeito da garantia dos direitos, em especial à saúde, e ao exercício da cidadania da população fronteiriça, devido à ausência da titularidade formal do direito à saúde garantido pela Constituição Federal Brasileira. A não titularidade apresenta implicações importantes para o SUS na medida em que, por si só, não barra a demanda de fronteiriços por assistência à saúde e pressiona os gestores dos municípios a atenderem estas demandas em saúde sem condições técnicas e recursos financeiros 2 . Além do atendimento a estas demandas ser realizado de maneira descontínua e fragmentada, uma vez que a legislação vigente prevê apenas assistência emergencial de saúde a esta população ${ }^{3}$.

A realidade das fronteiras do Brasil com os países do MERCOSUL foi identificada através da pesquisa Transpondo Fronteiras: Os Desafios do Assistente Social na Garantia do Acesso à Saúde no MERCOSUL 3, vinculada ao projeto Fronteira MERCOSUL: Um Estudo sobre o Direito à Saúde 4 . A pesquisa foi viabilizada por meio de convênio realizado entre a Universidade Federal de Santa Catarina (UFSC), através do Núcleo de Estudos Estado, Sociedade Civil e Políticas Públicas, e a 
Pontifícia Universidade Católica do Rio Grande do Sul (PUCRS), através do Núcleo de Estudos e Pesquisa em Saúde e Trabalho.

O artigo aborda, com centralidade, a questão da garantia do direito à saúde e da cidadania, bem como a circulação de pessoas e a dimensão da territorialidade, temas relacionados aos fluxos migratórios nas fronteiras do MERCOSUL. A revisão de literatura e os aportes teóricos e empíricos construídos na pesquisa supramencionada 3 tornaram possível inferir que a realidade das fronteiras traz determinações complexas no que se refere à constituição da cidadania e ao acesso à saúde na região, uma vez que os sistemas nacionais de saúde, dos países, são diferenciados em termos de universalidade, eqüidade, modelos de cobertura e atenção, modalidades de oferta e financiamento.

Sem a pretensão de esgotar a temática, fazem-se alguns apontamentos de ordem teórica sobre o contexto das fronteiras do MERCOSUL, considerando as alterações da dinâmica societária, o constante surgimento de novas demandas e a acentuada fragilização do Estado-nação e da garantia do direito à saúde neste contexto. Parte-se do princípio de que, no âmbito de um acordo como o MERCOSUL, voltado para o avanço da integração regional, mas fundamentalmente calcado no plano econômico, de integração de mercados 5, a discussão do direito à saúde e da cidadania requer uma perspectiva analítica que considere as diferenças do contexto social, econômico e jurídico, das legislações e normatizações dos sistemas nacionais de saúde da região e as fronteiras como espaço onde se estabelecem relações sociais entre povos com culturas particulares.

Nesse sentido, a discussão é direcionada por dois elementos: a cidadania nacional e a dimensão da territorialidade para além dos limites geográficos dos Estados-nação. Sob esse prisma, o trabalho está articulado em dois tópicos. No primeiro, trata-se da dimensão social no MERCOSUL e da livre circulação de pessoas e no segundo, são levantados alguns elementos para a discussão do conceito de cidadania nacional e da dimensão da territorialidade no processo de integração social do MERCOSUL.

\section{A dimensão social no MERCOSUL e a livre circulação de pessoas}

O MERCOSUL, constituído em 1991, quando Argentina, Brasil, Paraguai e Uruguai firmaram o Tratado de Assunção (http://www.mercosul. gov.br/textos/default.asp?Key=45), "caracterizase através do modelo de integração econômica regional intergovernamental e define seu obje- tivo na consolidação de um mercado comum" 6 (p. 355).

Dentre os tipos de integração regional, o Bloco constitui-se, atualmente, de uma união aduaneira com vistas à formação de um mercado comum ${ }^{6}$. Esta futura etapa requer a liberalização da circulação de mercadorias, pessoas, serviços e capitais sem obstáculos para a entrada e saída no interior de cada Estado Membro da integração 6,7 e representa o momento para as supressões das barreiras aos intercâmbios desses fatores, especialmente no que se refere às questões de abertura das fronteiras 7 para o trânsito de pessoas, seja para migração em busca de trabalho, produtos e serviços nos países vizinhos, como é o caso da assistência à saúde. A criação do MERCOSUL “abre um novo cenário para os movimentos populacionais e dos trabalhadores em particular, uma vez que a livre circulação é componente essencial de um mercado comum" 8 (p. 73).

Nas fronteiras a população circula de um país a outro na tentativa de suprir suas necessidades de saúde tanto no setor público como no setor privado ${ }^{3}$. Linares et al. 9 (p. 20) apontam essa realidade na tríplice fronteira Argentina/Brasil/ Paraguai onde "famílias de brasiguaios (...) procuram no Brasil atendimento nos serviços públicos de saúde (...), educação e assistência social".

A etapa do mercado comum prevê a livre circulação como meta fundamental, bem como a harmonização legislativa ${ }^{6}$. No entanto, alguns fatores como a heterogeneidade sócio-econômica entre os países e a baixa institucionalização da dimensão sócio-laboral têm retardado a incorporação do direito da livre circulação à agenda do MERCOSUL 8.

Nessa fase, o acordo prevê a construção de um espaço economicamente integrado após 2006, quando será observada como característica: “ $a$ presença das liberdades básicas, quais sejam, a livre circulação de mercadorias, livre circulação de capitais, livre circulação de trabalhadores e liberdade de estabelecimento. Essas liberdades é que permitirão a consolidação da integração plena entre os parceiros estatais envolvidos" 6 (p. 357).

Todavia, para que a fase de mercado comum se efetive como de integração plena, há a necessidade da regulação da livre circulação de pessoas. No caso dos trabalhadores, há a perspectiva de delimitar a categoria ou classe à qual será possibilitada a livre circulação; o estabelecimento de normas que permitam o ingresso e a permanência no país de acolhida; e as condições em que devem prestar o trabalho 6 .

Cada Estado Membro que receber trabalhadores estrangeiros deverá regulamentar suas garantias da mesma maneira como as dos trabalhadores nacionais, incluindo o acompanhamento 
de suas famílias. Tal ação deverá vir acompanhada, por exemplo, da harmonização de currículos escolares, incluindo a validação de diplomas acadêmicos e de habilitação profissional 6 .

Jaeger 6 e Draibe 10,11 destacam a importância da harmonização legislativa entre os Estado Membros, sobretudo das questões trabalhistas e previdenciárias, incluindo a assistência social e demais políticas sociais. Para os Estados Membros que recebem os trabalhadores serão necessárias "as garantias da ordem, da saúde e da segurança pública, [...] uma uniformização dos procedimentos nas fronteiras externas quanto às políticas de ingresso de estrangeiros e concessão de asilos e vistos diplomáticos" 6 (p. 358), assim como a superação das diversidades entre as políticas de saúde no sentido de garantir o acesso a ela em outros países do Bloco, favorecendo a livre circulação das pessoas 12 .

A constituição do mercado comum, ao contemplar a livre circulação como uma das liberdades fundamentais, centraliza-se na livre circulação de trabalhadores que desempenham atividade econômica assalariada. Os trabalhadores não assalariados ou independentes são englobados no conceito de liberdade de estabelecimento ou de direito à livre circulação de serviços. O Tratado de Assunção, quando expressa que o "mercado comum implica 'a livre circulação de bens, serviços e fatores produtivos entre os países', implica a liberdade restrita de trabalhadores, do homem enquanto fator produtivo, presença essa que reafirma o objetivo estritamente comercial desse processo" 6 (p. 359).

Sendo assim, a livre circulação de trabalhadores, que deveria ser analisada " a partir del enfoque que supone considerarlos como personas y no como recursos o factores productivos" 7 (p. 62), aparece timidamente em meio à preferência econômica 5. O Tratado de Assunção não menciona o envolvimento social dos cidadãos e das respectivas comunidades 5. Sua ênfase é referida ao desenvolvimento econômico, em detrimento da preocupação com as políticas sociais que tornem o cidadão participante do processo de integração ${ }^{6}$.

Emgeral, processos deintegraçãoregionalsurgem com objetivos econômicos, e no MERCOSUL o privilegiamento quase único dessa dimensão faz com que o acordo careça da dimensão social 5. Mesmo que esta não seja sua finalidade, o Tratado de Assunção faz referência ao desenvolvimento com justiça social 6,8. No entanto, nem a criação do Foro Consultivo Econômico e Social e dos Subgrupos de Trabalho (SGT), vinculados ao Grupo Mercado Comum, em especial o SGT 10 - dedicado à análise das questões trabalhistas - e o SGT 11 - dedicado às questões de saúde
-, determinou um comprometimento com a dimensão social no MERCOSUL, marginalizando a discussão da livre circulação de pessoas ${ }^{6}$.

É reconhecido, porém, que, na década de 1990, a dimensão social da integração ganhou amplitude sob distintas perspectivas 10. Dentre as áreas sociais privilegiadas no processo de integração com a criação de instituições e/ou acordos, medidas legais e documentos estão: a educação, a seguridade social, os aspectos laborais, as questões relacionadas às mercocidades, a construção de um sistema de indicadores sociais e a integração fronteiriça 10.

Contudo, "no hay una agenda social autónoma del MERCOSUR, aunque las dimensiones sociales de la integración estén presentes en las preocupaciones de algunos de los subgrupos de trabajo originales" 11 (p. 3). Draibe se refere à construção institucional da integração social no MERCOSUL em sentido ambicioso, ou seja, a instituição de "una nueva ciudadanía social, apoyada en un sistema de derechos y enraizada en una lógica de solidaridad 'unificada' y suficientemente fuerte para representarse ante la nueva institucionalidad que viene sendo gestada" 11 (p. 4).

$\mathrm{O}$ instrumento viabilizador da construção da cidadania social no MERCOSUL seriam as políticas sociais integradas ou unificadas 10,11 , considerando, no entanto, a forte heterogeneidade e fragilidade com que são organizadas e regulamentadas política e financeiramente no plano interno de cada país e as alterações dessas políticas nos Estados-membros mediante desregulação proposta pelos processos de reforma do Estado 11. Esses fatores tendem a dificultar o processo de unificação das políticas sociais e reduzir as possibilidades de construir uma agenda para a integração social na região.

Algumas discussões são realizadas em fóruns regionais nos limites de cada fronteira, como nas comissões binacionais de saúde; nas comissões regionais de fronteira ligadas às coordenadorias regionais de saúde no Brasil; nos fóruns regionais de gestores de municípios de fronteira; por intermédio de contatos e acordos entre os consulados para encaminhar questões de saúde, assistência social, legalização da documentação ${ }^{3}$. Coordenado pela Itaipu Binacional, existe um grupo de trabalho que trata das questões referentes à saúde nas fronteiras e da articulação de ações e serviços entre as municipalidades brasileiras e dos países vizinhos, no âmbito informal, para a assistência da população fronteiriça ${ }^{3}$. São iniciativas e ações formais e informais, unilaterais ou bilaterais, que, de um lado, apontam para uma integração regional para além dos aspectos econômicos, na qual a livre circulação de pessoas - legalizada ou não - é inevitável, causando 
impactos e repercussões no setor de saúde. Por outro lado, sinalizam que, para a constituição do mercado comum, é necessária a transposição de barreiras físicas e jurídicas que impeçam a livre circulação das pessoas ${ }^{3}$.

Jaeger 6 (p. 362) assinala que o maior desafio do mercado comum é o estabelecimento do direito à livre circulação de pessoas valendo-se da eliminação “de todos os tipos de restrições à sua mobilidade, igual tratamento e garantias de não-discriminação em razão da sua nacionalidade...". Nisso está a supressão dos controles no cruzamento das fronteiras e o reconhecimento da busca, em outro país, de emprego/trabalho e serviços de proteção social para alcançar melhor condição de vida.

O controle dos cruzamentos nas fronteiras suscita a discussão dos movimentos e políticas migratórias no MERCOSUL. As fronteiras possuem instalações e órgãos governamentais como aduanas, gendarmerias e destacamentos militares instalados em pontos estratégicos a fim de controlar o trânsito e a circulação interfronteiriça de pessoas, coisas ou mercadorias 13 . A rigidez com que o espaço fronteiriço ainda é tratado no processo integracionista demonstra que as fronteiras são percebidas, pelos governos centrais, como espaços de conflito 8 ou como áreas de segurança nacional 14, desconsiderando os movimentos migratórios internacionais como fator de desenvolvimento econômico e social ${ }^{8}$.

O tema das migrações internacionais tem sido abordado com profundidade por alguns autores, dentre os quais, Sprandel 15,16; Castro 17; Milesi \& Bassegio 18, Milesi et al. 19, e por instituições e movimentos sociais como la Coordenadora de Centrales Sindicales del Conosur (CCSCS), a Comissão Nacional de População e Desenvolvimento (CNPD), o Centro Latinoamericano e Caribeño de Demografia (CELADE), o Serviço Pastoral dos Migrantes (SPM) e a Organización Internacional para las Migraciones (OIM) que discutem o tratamento às migrações e as políticas migratórias nos diversos âmbitos e espaços, com a preocupação de considerar a situação e a garantia dos direitos humanos dos migrantes, tanto brasileiros no exterior como estrangeiros no Brasil. Quanto aos movimentos migratórios no MERCOSUL, são importantes as contribuições de Sprandel 20; Patarra 21; Patarra \& Baeninger 22,23; Kratochwill 13 e Silva 24.

As migrações internacionais ganham destaque no contexto do MERCOSUL, uma vez que a permeabilidade das fronteiras vem contribuindo para que se intensifiquem os deslocamentos migratórios intrabloco 22,23, particularmente, em busca de acesso/uso alternativo de serviços sociais de um lado ou outro da fronteira 13.
Estes processos migratórios exigem uma análise que contemple sua complexidade, considerando, como indica Mármora 25 (p. 174), suas causas - "procesos globales de la sociedad, en el que la problemática básica se expresa en la relación de desequilibrio socioeconómico entre los países y/o regiones"; suas características - composição do movimento migratório, formas e tipos de migração; e seus efeitos - "económicos", "sóciolaborales", "sócio-culturales", “psico-sociales” e "psicopatológico".

O exame das migrações com base nesses diversos ângulos permite, segundo Mármora 25 (p. 175) “elaborar políticas globales que logren dar respuestas a los múltiples problemas que plantean", bem como, possibilitar o surgimento de políticas sociais integradas; potencializar ações já existentes entre os Estados Membros que atendam as demandas e garantam os direitos da população migrante, sem desconsiderar os impactos e as trocas culturais estabelecidos entre os povos, proporcionados pelo trânsito entre os países 26,27 . Observar os processos migratórios na perspectiva de sua amplitude significa considerá-los históricos (que se desenvolvem entre os países desde longa data) e que envolvem outras formas de mobilidade no(s) território(s) (não somente a mudança de residência ou endereço fixo, mas a mobilidade temporal e circular, em geral, associadas aos ciclos e atividades econômicas e a busca de serviços de proteção social nas fronteiras) 22,23 .

Assim, na tentativa de corrigir as debilidades do processo de integração foram estabelecidas as comunidades fronteiriças, que pretendem facilitar o fluxo migratório, a circulação de pessoas e trabalhadores, o acesso à documentação e aos direitos à assistência, à saúde e à seguridade social para a população fronteiriça 10 .

A secundarização da dimensão social no MERCOSUL torna a busca da população fronteiriça por assistência à saúde no SUS uma questão invisível na agenda de discussão dos gestores dos países ${ }^{3}$. A invisibilidade política da procura por serviços de saúde na região advém de que as fronteiras, enquanto espaços de separação e de limite entre os Estados nacionais, “... han permanecido invisibles durante mucho tiempo" 28.

Mesmo assim, os gestores municipais não conseguem estabelecer acordos efetivos para a resolução dos problemas de saúde sem que as tratativas sejam discutidas interministerialmente, pois estão envolvidos recursos humanos e financeiros além dos disponíveis. Ou seja, os municípios fronteiriços não podem firmar convênios ou protocolos de atendimento com cidades estrangeiras prevendo repasses financeiros $\mathrm{e}$ circulação de profissionais de saúde. 
Existe a iniciativa do Ministério da Saúde do Brasil, de implantar o Sistema Integrado de Saúde das Fronteiras (SIS-Fronteiras), um projeto voltado para fazer frente ao déficit de recursos financeiros dos municípios brasileiros que atendem a população fronteiriça no SUS 3 .

A implantação do SIS-Fronteiras pode vir acompanhada de um sistema de controle, a fim de não se tornar mera declaração de intenções e se resumir a um projeto verticalizado com mero repasse financeiro sem, de fato, discutir a integração do setor saúde no MERCOSUL ${ }^{3}$. Nessa direção, um mecanismo seria o estabelecimento de órgão supranacional que exigisse seu cumprimento frente aos Estados Membros 6. Novas realidades institucionais internacionais com capacidade de governo 11 capazes de conduzir os conflitos e garantir aos Estados Membros as vantagens da integração regional 10 .

Bobbio ${ }^{29}$, em contrapartida, aponta os organismos internacionais como reguladores do cumprimento de direitos. As atividades implementadas por eles, tendo em vista a tutela dos direitos, podem ser consideradas sob os aspectos da promoção, do controle e da garantia 29 .

Em que pesem as diferenças entre as proposições de constituição de instituições/órgãos supranacionais e/ou de organismos internacionais como reguladores dos direitos, o que parece fundamental é a referência a uma cidadania supranacional comunitária 10 fundada em direitos sociais mínimos comuns, que, para sua efetivação, exigem um processo unificador de políticas sociais.

No MERCOSUL, a garantia e a realização desses direitos passam, além do vetor econômico, que influencia sobremaneira os países em desenvolvimento, por condições objetivas de transposição de outras duas barreiras: a cidadania nacional e a dimensão da territorialidade.

Cidadania nacional e território: elementos para pensar a integração social no MERCOSUL

A concepção de cidadania desenvolvida por Marshall pode ser considerada a mais influente na modernidade, pois o avanço de sua análise consiste no estabelecimento das características constitutivas da cidadania moderna: universalidade, territorialização, individualização e índole estatal-nacional da cidadania 30.

Esses elementos sustentaram o desenvolvimento da cidadania calcada num status concedido aos indivíduos que são membros de determinada comunidade, definida territorialmente num país, composta de classes sociais em situação de desigualdade e relacionada a um Estado centralizador do poder.
A síntese cronológica da constituição dos direitos de cidadania integrantes da condição de cidadão desenvolvida por Marshall 31 demarca que a "cidadania é constituída por um conjunto de direitos formais, promulgados por lei, garantidos e implementados pelo Estado, estabelecendo-se, dessa forma, uma relação entre o cidadão e a unidade estatal no que concerne a direitos e obrigações" 32 (p. 14).

Nesta perspectiva, a relação entre cidadão e Estado-nação remete à relação entre cidadania e nacionalidade na medida em que, por meio de um conjunto de práticas políticas, sociais, culturais e econômicas, considera-se o "indivíduo como cidadão e membro de uma comunidade, apresentando como característica essencial a vontade de pertencer a essa coletividade" 32 (p. 14) e, nessa comunidade política, compartilhar crenças, língua, costumes, tradições, valores e identidade.

A dimensão da nacionalidade encontra-se vinculada à idéia de nação, como unidade territorial geograficamente localizada, e à idéia de Estado moderno como expressão política de sua organização ${ }^{33}$. Portanto, o pertencimento a uma comunidade política passou a determinar a instituição da cidadania.

Historicamente, a nacionalidade constitui um projeto sustentado pela delimitação de um território, dirigido por um Estado forte e centralizador e acompanhado de uma esfera jurídica 33. Na América Latina, a quase totalidade das cartas constitucionais - formuladas entre 1829 e 1870 "definem a nacionalidade apoiando-se no antigo direito romano do jus soli” 33 (p. 35), da nacionalidade adquirida pelo nascimento num determinado território. No século XX, essas leis sofreram reformulações contemplando a obtenção da nacionalidade por meio do jus sanguinis 33 .

Para Ballarino 34, a vinculação estabelecida entre nacionalidade e Estado-nação alicerçou o conceito tradicional de cidadania - cidadania nacional -, e o termo nacionalidade consolidou-se no sentido de indicar a pertença de uma pessoa a determinado Estado.

Entretanto, o conceito de cidadania é ampliado com o crescente dinamismo econômico, com o fortalecimento do regionalismo e com a criação de instituições supranacionais. Exemplo disso é o progresso da cooperação política estabelecida na União Européia, que determinou o surgimento de realidades em que a cidadania perde seu valor exclusivo em favor da pertença a uma União 34 - Cidadania Comunitária ou Cidadania da União 5 .

A idéia da cidadania regional, com a característica de ser ampliada, derivou do processo de integração econômica européia. É uma cidadania superposta, complementar, uma dupla cida- 
dania, porque não substitui a cidadania nacional dos Estados Membros da união ou do acordo regional ${ }^{32}$. A "cidadania dos Estados Membros e a cidadania comunitária não são excludentes" 5 (p. 82).

O avanço dos processos de integração regional e a especificidade do artifício supranacional abrem nova perspectiva à cidadania, em que a "supranacionalidade vem conferir-lhe uma segunda identidade, que não substitui nem suprime a cidadania nacional do cidadão comunitário. Trata-se de uma cidadania adicional, uma segunda plataforma" 32 (p. 15-6).

Os direitos da cidadania comunitária não substituem, prejudicam ou impedem a titularidade e o exercício dos direitos que cada país define em sua esfera jurídica. Seu estatuto, ao contrário, é de sobreposição, ou seja, a cidadania comunitária é um plus àquela cidadania que os nacionais detêm nos Estados Membros 5 .

Dessa forma, o cenário mundial globalizado e o desafio de promover a articulação das nações por intermédio do regionalismo tencionam a uma mudança do conceito de cidadania nacional para o de cidadania regional ou comunitária, tendo como característica a dissociação da nacionalidade 32 .

Nesta direção, organizações e movimentos sociais em defesa dos migrantes, reunidos nos I e II Fórum Social Mundial das Migrações, realizados em Porto Alegre (2005) e Madrid (2006), defendem a afirmação de uma cidadania universal 35 e de direitos inerentes à condição de cidadão, sem vincular-se à nacionalidade, estendidos a todos os migrantes 36 .

Esses movimentos favoreceriam a extensão da cidadania aos indivíduos considerados não cidadãos (estrangeiros) e a qualquer pessoa: "residente ou não residente no território de um Estado..." 32 (p. 16).

A ampliação do conceito de cidadania para além das bases territoriais dos Estados-nação vem ao encontro de uma mudança na conformação do espaço e das relações entre as nações em nível mundial nos últimos tempos. Com o processo da globalização indica-se também a busca pela retomada da cidadania no âmbito internacional. Trata-se de uma busca para além do mercado, que ultrapasse o âmbito dos acordos e relações econômicas de integração entre os países, que se realize na perspectiva de uma integração cultural, social e política.

Isso significa que, simultaneamente à evolução dinâmica e singular dos processos de regionalismo e globalização o conceito de cidadania deve transcender os "limites do Estado e da nacionalidade (...) projetando tanto um novo tipo de cidadania - a cidadania mundial - como um novo tipo de cidadão - o cidadão do mundo" 32 (p. 13).

A transcendência da dimensão nacional do conceito de cidadania, estreitamente concebida em termos de área geográfica 1 , implica discutir a dimensão da territorialidade na garantia dos direitos, em especial do direito à saúde, no MERCOSUL.

Essa dimensão ganha relevância quando da discussão das categorias direito e cidadania no espaço de integração regional, já que a garantia da primeira e o exercício da segunda estão assegurados com base no Estado-nação delimitado territorialmente aos cidadãos pertencentes a uma comunidade política. Vale dizer, "la idea de derechos ciudadanos - civiles, políticos y sociales - remite a la construcción de los Estados nacionales, es decir, de un poder político que se ejerce en forma soberana y autónoma sobre un territorio y un pueblo, unidos por una historia y una cultura comunes" 37 (p. 3).

O território pode ser considerado como um espaço geográfico, histórico e político construído mediante relações entre diferentes atores que determinam o conjunto de condições em que vive a população e pressupõem articulação entre dinâmica demográfica e dinâmica sócio-territorial 38. "O território deve ser considerado em suas divisões jurídico-políticas, suas heranças históricas e seu atual conteúdo econômico, financeiro, fiscal e normativo" 39 (p. 84).

O componente territorial supõe uma instrumentação do território capaz de atribuir a todos os habitantes bens e serviços indispensáveis, não importa onde esteja a pessoa; e uma adequada gestão do território, pela qual a distribuição geral dos bens e serviços públicos seja assegurada 40 .

Assim, considera-se que uma concepção de território que extrapole os limites geográficos é fundamental para pensar as fronteiras como possibilidade de avançar nas reflexões sobre a mobilidade dos indivíduos, pois esta é condicionada por razões sócio-econômicas e de desigualdades sociais e territoriais existentes nas regiões subdesenvolvidas da sociedade capitalista 40 .

Na situação brasileira, no que se refere às migrações internas, a questão da mobilidade está relacionada ao consumo e ausência de acesso a serviços 18,40 . Suas causas são verdadeiras migrações forçadas e freqüentemente "ligadas ao consumo e à inacessibilidade a bens e serviços essenciais" 40 (p. 44).

A análise de Santos 39,40 a respeito da mobilidade no território brasileiro no sentido de buscar acessibilidade a serviços essenciais auxilia a pensar a situação nas fronteiras do MERCOSUL. De um lado, há uma parcela significativa da população brasileira que migrou/migra para o 
Paraguai e Uruguai em busca de trabalho 18,20,22,23 e por outro lado, há uma mobilidade de estrangeiros e brasiguaios que migraram para estes países e retornam ao Brasil buscando acesso à saúde pela impossibilidade de ingresso nos centros de referência no país de origem pelas longas distâncias e escassez de recursos na área ao longo das fronteiras e por ela ser uma zona periférica, em geral desprovida de investimentos governamentais 3 .

Essas situações fazem com que a localização dos indivíduos no território seja produto de uma combinação entre forças de mercado e decisões de governo. Como o resultado é independente da vontade dos indivíduos atingidos, fala-se de (i) migrações ou localizações forçadas 39,40.

O componente territorial torna-se, assim, imprescindível na consolidação de uma política de saúde efetivamente inclusiva nas fronteiras do MERCOSUL, em que os indivíduos não sejam discriminados em função do lugar onde vivem. Sua incorporação na formulação de políticas de saúde para a região deve romper com a valorização do indivíduo por causa de sua localização no território 40.

Isso significa pensar a organização territorial e a gestão do espaço como instrumentais para uma política redistributiva, tendente à atribuição de justiça social para a totalidade da população, não importa onde esteja cada indivíduo ${ }^{40}$. A incorporação da dimensão territorial na gestão das políticas sociais nas fronteiriças pode concretizar-se numa lei, portaria, decreto ou programa, visto que desse modo "surge e se impõe a categoria jurídica do cidadão, ou, ainda melhor, o cidadão como categoria jurídica" 40 (p. 80).

Atualmente, no MERCOSUL, a discussão de uma política de saúde efetivamente redistributiva e acessível a todos os indivíduos caminha para tratativas intergovernamentais que indicam sua concretização em longo prazo. Mudanças no uso e na gestão do território se impõem, caso se deseje criar um novo tipo de cidadania que ofereça respeito à cultura 40 .

A discussão do trânsito para além dos limites territoriais entre os países do MERCOSUL, quanto ao acesso à assistência à saúde, deve levar em consideração os fatores sociais, econômicos, geográficos e culturais, já que é possível constatar a ausência e precariedade de serviços e equipamentos sociais como instituições hospitalares, postos de saúde, serviços de atenção geral e especializados ${ }^{3}$. As fronteiras são áreas desprovidas de serviços essenciais à vida social e individual forçando brasileiros e estrangeiros a migrarem, temporária ou definitivamente, pelas condições de renda, trabalho e serviços sociais oferecidos em outros países 22,23 .
Dessa forma, reafirma-se a importância da dimensão territorial ser contemplada por mecanismos legais, possibilitando que a cidadania e os direitos possam ser estendidos igualmente para todos independentemente de fatores restritivos 40 . Todavia, sem perder de vista que o estabelecimento da norma jurídica não esgota a luta pela cidadania e pelos direitos, o cidadão, valendo-se das conquistas obtidas, tem de permanecer alerta para garanti-los e ampliá-los.

Nessa direção tem importância o aprofundamento do debate, nas diferentes áreas do conhecimento sobre a construção, extensão e ampliação da cidadania e do direito à saúde nas fronteiras. O referencial da cidadania nacional voltada para o interior do Estado-nação, além de ser restrito, não privilegia a mobilidade dos indivíduos, como se estes estivessem limitados ao espaço de seu país. Tal modelo não abrange a amplitude e complexidade das fronteiras do MERCOSUL.

Como não pensar em estender a cidadania aos não-cidadãos que possuem o direito à mobilidade espacial, o direito civil de ir e vir, que, em países subdesenvolvidos, significa ter outros motivos que somente querer exercer um direito civil, mas sim exercer um direito social, um direito à vida - que significa o acesso à assistência à saúde - mesmo que num país, num território, numa nacionalidade, num espaço que não é seu nem o reconhece como cidadão ${ }^{3}$.

\section{Considerações finais}

A garantia do direito à saúde de forma gratuita $\mathrm{e}$ universal no Brasil tem atraído significativo fluxo da população fronteiriça, advinda dos países do MERCOSUL, em busca de assistência no SUS, sobretudo, pelo déficit de serviços e ações oferecidos nos países de origem. A não titularidade jurídico-formal de cidadãos brasileiros desta população leva a reforçar a assertiva de que a direção da discussão sobre o exercício da cidadania e da garantia do direito à saúde possui intrínseca relação com os aspectos legais, uma vez que estas duas categorias se expressam por meio de diferentes normatizações em cada Estado Membro e, em geral, se referem aos indivíduos considerados membros de determinada comunidade política definida territorialmente.

Essas normativas desconsideram as tentativas do passado e do presente de estabelecer processos de integração regional, mesmo que se valendo da constituição de blocos centrados nos aspectos econômicos.

A transcendência desta discussão e a incorporação a ela de um conceito de cidadania ampliada e da territorialidade que contemple as 
particularidades das fronteiras ainda encontra como barreira a prevalência dos interesses econômicos do Acordo em detrimento da dimensão social. Ainda é invisível às negociações governamentais que discutir a conformação do direito à saúde e sua garantia no MERCOSUL é tratar do desvelamento de um conjunto de necessidades sociais, econômicas, políticas, culturais e geográficas que forçam parcela da população desses países a buscar atendimento à saúde no sistema brasileiro.

Os acordos de cooperação no âmbito central ou intermunicipal, entre os Estados Membros para a conformação do direito à saúde e para o atendimento da população fronteiriça se encaminham para concretização em longo prazo, dificultando a efetivação do acesso dessa população pela falta de respaldo legal e desfavorecimento dos aspectos sociais.

\section{Resumo}

O artigo aborda, mediante revisão teórica, a garantia do direito à saúde e do exercício da cidadania na linha das fronteiras do Brasil com os países do MERCOSUL (Argentina, Paraguai e Uruguai) tendo em vista o trânsito interfronteiras e a demanda gerada pela população fronteiriça ao Sistema Único de Saúde (SUS). O objetivo é discutir a garantia do direito e da cidadania, bem como a livre circulação de pessoas e a dimensão da territorialidade, temas correlacionados ao trânsito da população fronteiriça nos municípios brasileiros. Identifica-se a predominância da dimensão econômica no MERCOSUL em detrimento dos avanços regulatórios/legais referentes à dimensão social e à previsão da livre circulação de pessoas intrabloco. A análise é realizada por intermédio dos elementos da cidadania nacional e do território quando se pensa na extensão do direito à saúde à população fronteiriça. Leva-se em consideração a requisição de alternativas à extensão dos direitos e do estabelecimento e ampliação das políticas sociais públicas em saúde na linha das fronteiras do MERCOSUL para o atendimento da demanda fronteiriça que busca assistência no SUS.

Direito à Saúde; Áreas de Fronteira; Política de Saúde
Enquanto as discussões entre os ministérios da saúde não avançam para a concretização da resolução da problemática do atendimento à saúde nas fronteiras do MERCOSUL, os municípios brasileiros arcam com o atendimento da demanda da população fronteiriça sem terem condições financeiras e recursos humanos. Por outro lado, os fronteiriços desenvolvem estratégias para garantirem a acessibilidade à saúde, mesmo que para a resolução urgente de sua situação.

O estabelecimento dessas estratégias é incentivado pela circulação restrita (não livre) de pessoas nas fronteiras do MERCOSUL - que faz com que a exigência da documentação ou naturalização brasileira seja a forma para o acesso e inclusão à assistência à saúde -; pela definição do status de cidadão restrito à cidadania nacional $\mathrm{e}$ pela importância do território onde se encontra o indivíduo.

\section{Colaboradores}

K. R. Dal Prá elaborou, organizou o artigo e participou de sua reformulação. J. M. R Mendes participou da organização e reformulação e R. C. T. Mioto participou da reformulação do artigo. 


\section{Referências}

1. Nogueira VMR, Simionatto I, Silva MG. Fronteira MERCOSUL - processos de inclusão/exclusão no Sistema Único de Saúde brasileiro. http://www. ssrevista.uel.br/ (acessado em 15/Set/2006).

2. Gallo E, Costa L, Moraes A. A integração dos sistemas de saúde que atendem a população fronteiriça dos países do MERCOSUL - SIS-MERCOSUL. In: Gallo E, Costa L, organizadores. SIS-MERCOSUL: uma agenda para integração. Brasília: Organização Pan-Americana da Saúde; 2004. p. 41-53. (Série Técnica: Projeto de Desenvolvimento de Sistema e Serviços de Saúde, 9).

3. Dal Prá KR. Transpondo fronteiras: os desafios do assistente social na garantia do acesso à saúde no MERCOSUL [Dissertação de Mestrado]. Porto Alegre: Pontifícia Universidade Católica do Rio Grande do Sul; 2006.

4. Nogueira VMR. Fronteira MERCOSUL: um estudo sobre o direito à saúde. Florianópolis: Universidade Federal de Santa Catarina; 2003.

5. Campos EN. O lugar do cidadão nos processos de integração: o déficit social da Comunidade Européia e do MERCOSUL. Belo Horizonte: Mandamentos Editora; 2002.

6. Jaeger AJ. MERCOSUL e o desafio da livre circulação de trabalhadores: dificuldades e perspectivas. In: Dal Ri Junior AJ, Oliveira OM, organizadores. Cidadania e nacionalidade: efeitos e perspectivas: nacionais, regionais e globais. Ijuí: Editora Unijuí; 2003. p. 349-75.

7. Murro-Oberlín ER. El dilema de la seguridad social en el Cono Sur. Lima: Organización Internacional del Trabajo; 2004.

8. Sant'ana MR. Livre circulação de trabalhadores no MERCOSUL? In: Castro MG, organizador. Migrações internacionais: contribuições para políticas. Brasília: Comissão Nacional de População e Desenvolvimento; 2001. p. 73-93.

9. Linares AGE, Krautsto E, Sprandel MA, organizadores. Situação das crianças e dos adolescentes na Tríplice Fronteira entre Argentina, Brasil e Paraguai: desafios e recomendações. Curitiba: Fundo das Nações Unidas para a Infância/Itaipu Binacional; 2005.

10. Draibe SM. Coesão social e integração regional: a agenda social do MERCOSUL e os grandes desafios das políticas sociais integradas. Cad Saúde Pública 2007; 23 Suppl 2:S174-83.

11. Draibe SM. MERCOSUR: la temática social de la integración desde la perspectiva institucional. http://www.top.org.ar/public.htm (acessado em $16 /$ Set/2006).

12. Guimarães L, Giovanella L. Integração européia e políticas de saúde: repercussões do mercado interno europeu no acesso aos serviços de saúde. Cad Saúde Pública 2006; 22:1795-807.

13. Kratochwill H. Migraciones, circulaciones de personas y política migratoria en el MERCOSUR. In: Patarra NL, editor. Emigração e imigração internacionais no Brasil contemporâneo. Campinas: Fundo das Nações Unidas para a População/São Paulo: Oficina Editorial; 1996. p. 155-66.
14. Ministério da Integração Regional. Proposta de reestruturação do programa de desenvolvimento da faixa de fronteira: bases para uma política integrada de desenvolvimento regional para a faixa de fronteira. Programa de Desenvolvimento da Faixa de Fronteira. Brasília: Secretaria de Programas Regionais, Ministério da Integração Regional; 2005.

15. Sprandel MA. O parlamento e as migrações internacionais. In: Castro MG, organizador. Migrações internacionais: contribuições para políticas. Brasília: Comissão Nacional de População e Desenvolvimento; 2001. p. 97-119.

16. Sprandel MA. Migrações internacionais e a sociedade civil brasileira. In: Castro, MG, organizador. Migrações internacionais: contribuições para políticas. Brasília: Comissão Nacional de População e Desenvolvimento; 2001. p. 547-62.

17. Castro MG. Migrações internacionais e políticas: algumas experiências internacionais. In: Castro MG, organizador. Migrações internacionais: contribuições para políticas. Brasília: Comissão Nacional de População e Desenvolvimento; 2001. p. 15-32.

18. Milesi R, Bassegio L. Migrantes, refugiados e os direitos humanos no Brasil. In: Faial E, Delgado G, Milesi R, organizadores. Direitos humanos no Brasil: 1992-1993. São Paulo: Edições Loyola; 1994. p. 35-52.

19. Milesi R, Bonassi M, Shimano ML. Migrações internacionais e a sociedade civil organizada: entidades confessionais que atuam com estrangeiros no Brasil e com brasileiros no exterior. In: Castro MG, organizador. Migrações internacionais: contribuições para políticas. Brasília: Comissão Nacional de População e Desenvolvimento; 2001. p. 563-87.

20. Sprandel MA. Brasileiros na fronteira com o Paraguai. Estud Av 2006; 57:137-56.

21. Patarra NL. Emigração e imigração internacionais no Brasil contemporâneo. Campinas: Fundo das Nações Unidas para a População/São Paulo: Oficina Editorial; 1996.

22. Patarra NL, Baeninger R. Mobilidade espacial da população no MERCOSUL: metrópoles e fronteiras. Rev Bras Ciênc Soc 2006; 60:83-102.

23. Patarra NL, Baeninger R. Migrações internacionais, globalização e blocos de integração econômica - Brasil no MERCOSUL. http:/ /www.abep.nepo. unicamp.br/site_eventos_alap/PDF/ALAP2004_ 244.pdf (acessado em 18/Jan/2007).

24. Silva MG. O local e o global na atenção às necessidades de saúde dos brasiguaios: análise da intervenção profissional do assistente social em Foz do Iguaçu [Dissertação de Mestrado]. Florianópolis: Universidade Federal de Santa Catarina; 2006.

25. Mármora L. El desafio de las políticas migratorias: su governabilidad. In: Patarra NL, organizador. Emigração e imigração internacionais no Brasil contemporâneo. Campinas: Fundo das Nações Unidas para a População/São Paulo: Oficina Editorial; 1996. p. 167-83. 
26. Mármora L. Politicas de migraciones en América Latina: las respuestas gubernamentales y de la sociedad civil en la década de los 90. In: Castro MG, organizador. Migrações internacionais: contribuições para políticas. Brasília: Comissão Nacional de População e Desenvolvimento; 2001. p. 33-44.

27. Ianni O. A sociedade global. Rio de Janeiro: Editora Civilização Brasileira; 1997.

28. González C. La frontera en debate: una discusión en torno a la integración regional y el futuro del Estado nación [CD-ROM]. Florianópolis: Universidade Federal de Santa Catarina; 2005.

29. Bobbio N. A era dos direitos. Rio de Janeiro: Editora Campus; 1992.

30. Lavalle AG. Cidadania, igualdade e diferença. Revista Lua Nova 2003; 59:75-94.

31. Marshall TH. Cidadania, classe social e status. Rio de Janeiro: Jorge Zahar Editor; 1967.

32. Dal Ri Junior AJ, Oliveira OM, organizadores. Cidadania e nacionalidade: efeitos e perspectivas: nacionais, regionais e globais. Ijuí: Editora Unijuí; 2003.
33. Ruben GR. O que é nacionalidade. São Paulo: Brasiliense; 1984.

34. Ballarino T. Cidadania e nacionalidade. In: Dal Ri Junior AJ, Oliveira OM, organizadores. Cidadania e nacionalidade: efeitos e perspectivas: nacionais, regionais e globais. Ijuí: Editora Unijuí; 2003. p. 85-93.

35. Guertechin TL. Síntese geral do Fórum Social das Migrações. http://www.fsmm2006.org/PDF/ 50\%20Enfoque\%20final\%20FSMig\%20Tierry.pdf (acessado em 19/Jan/2007).

36. Fórum Social Mundial das Migrações. Declaração de Rivas. http://www.fsmm2006.org/es/index.php (acessado em 19/Jan/2007).

37. Fleury S. La ciudad de los ciudadanos. http://www. top.org.ar/public.htm (acessado em 16/Set/2006).

38. Santos M. Espaço e método. São Paulo: Studio Nobel; 1985.

39. Santos M. O país distorcido: o Brasil, a globalização e a cidadania. São Paulo: Publifolha; 2002.

40. Santos M. O espaço do cidadão. São Paulo: Studio Nobel; 2000.

Recebido em 07/Nov/2006

Versão final reapresentada em 12/Fev/2007

Aprovado em 02/Mar/2007 